\title{
Translational Stroke Research Using a Rabbit Embolic Stroke Model: A Correlative Analysis Hypothesis for Novel Therapy Development
}

\author{
Paul A. Lapchak
}

Received: 11 January 2010 /Revised: 28 January 2010 / Accepted: 11 March 2010 /Published online: 2 April 2010

(C) The Author(s) 2010. This article is published with open access at Springerlink.com

\begin{abstract}
Alteplase (tissue plasminogen activator, tPA) is currently the only FDA-approved treatment that can be given to acute ischemic stroke (AIS) patients if patients present within $3 \mathrm{~h}$ of an ischemic stroke. After 14 years of alteplase clinical research, evidence now suggests that the therapeutic treatment window can be expanded $4.5 \mathrm{~h}$, but this is not formally approved by the FDA. Even though there remains a significant risk of intracerebral hemorrhage associated with alteplase administration, there is an increased chance of favorable outcome with tPA treatment. Over the last 30 years, the use of preclinical models has assisted with the search for new effective treatments for stroke, but there has been difficulty with the translation of efficacy from animals to humans. Current research focuses on the development of new and potentially useful thrombolytics, neuroprotective agents, and devices which are also being tested for efficacy in preclinical and clinical trials. One model in particular, the rabbit small clot embolic stroke model (RSCEM) which was developed to test tPA for efficacy, remains the only preclinical model used to gain FDA approval of a therapeutic for stroke. Correlative analyses from existing preclinical translational studies and clinical trials indicate that there is a therapeutic window ratio (ARR) of 2.43-3 between the RSCEM and AIS patients. In conclusion, the RSCEM can be used as an effective translational tool to gauge the clinical potential of new treatments.
\end{abstract}

Keywords Neuroprotection - Embolism · Acute ischemic stroke - Clinical - Behavior - Toxicity - Translational science . Antioxidant · Laser $\cdot$ Radicut $\cdot$ NXY-059 · Thrombolytic . Penumbra

\section{P. A. Lapchak $(\bowtie)$}

Department of Neurology, Cedars-Sinai Medical Center,

8730 Alden Drive, Thalians E216,

Los Angeles, CA 90048, USA

e-mail: Paul.Lapchak@cshs.org

\section{Introduction}

Stroke Incidence

AIS is the third leading cause of death and the leading cause of adult disability in the USA [1] with an estimated cost of $\$ 68.9$ billion. According to the current 2009 USA stroke statistics [2], each year, approximately 795,000 people suffer a stroke (one every $40 \mathrm{~s}$ with one mortality every $3 \mathrm{~min}$ ), $75 \%$ of which are first strokes and the remainder recurrent attacks. Annually, $18 \%$ of stroke victims die from the brain attack. Gender differentially impacts mortality rates with $60.6 \%$ of females dying from a stroke compared to $39 \%$ of male victims [2]. The World Health Organization estimates that 15 million people suffer strokes worldwide. More than five million stroke victims die from the brain insult and approximately 5.5 million are permanently disabled (www.strokecenter.org/patients/stats.htm).

\section{Ischemic Stroke Classification}

According to the National Institutes of Neurological Disorders and Stroke (NINDS) type classification and the population-based study documented by Petty et al. [3, 4], AIS can be classified as the following:

1. Cardioembolic stroke in which the embolism arises from a cardiac source such as atrial fibrillation with intra-atrial thrombus, congestive heart failure, myocardial infarction, valve disease, and aneurysm surgery;

2. Atheroembolic stroke which can be associated with narrowing of a cervicocephalic artery (i.e., large artery to artery stroke) including the carotid, vertebral, basilar, middle cerebral, anterior cerebral, or posterior cerebral artery; and 
3. Small vessel lacunar stroke which is defined as pure motor, sensorimotor, or sensory strokes in addition to ataxic hemiparesis and result from thrombosis in one of the deep penetrating branches from larger cerebral arteries.

According to Petty and colleagues [3, 4], in patients with strokes with known causes, cardioembolic stroke is a predominant subtype in AIS patients making up approximately $29 \%$ of the population, whereas both atheroembolic and lacunar stroke are represented by $16 \%$ of the population. However, it remains that the majority of strokes (39\%) do not have a known cause and are identified as "cause unknown." Independent of the type of stroke, the "clot" is responsible for the interruption of cerebral blood flow [5-7], thereby changing tissue metabolism, depleting cells of energy stores, and, depending upon the duration of the initial insult, can trigger a cascade of excitotoxicity, free radical formation, blood-brain barrier (BBB) injury, and inflammation [6]. Reduced blood flow and severe oxygen deficiency leads to an ischemic brain area comprising a central core of severely ischemic tissue surrounded by a tissue zone consisting of moderate ischemic tissue with preserved cellular metabolism and viability [8-10]. For a yet undefined period of time after a stroke, there appears to be a region of salvageable tissue commonly referred to as a "penumbra" to target with novel therapies in order to improve cellular functions.

\section{Current Treatment}

The only FDA-approved treatment for stroke is the thrombolytic, tissue plasminogen activator (tPA, Alteplase ${ }^{\circledR}$, Activase $^{\circledR}$ ) marketed by Genentech Inc. in the USA and Boehringer Ingelheim in Europe as actilyse ${ }^{\circledR}$. tPA is a plasminogen activator that promotes thrombolysis by activating the endogenous fibrinolytic system [5, 11-13]. In brief, tPA catalyzes the conversion of plasminogen to plasmin, which in turn degrades fibrin and leads to clot lysis and cerebral reperfusion. Alteplase has been shown to be effective up to $4.5 \mathrm{~h}$ after a stroke $[14,15]$. However, alteplase therapy has been linked to serious, even fatal, side effects [5]. Although the mortality rate at 90 days post-treatment is similar in alteplase and placebo groups, the short-term incidence of symptomatic intracerebral hemorrhage (sICH) is significantly higher in tPA-treated patients. In the NINDS tPA trial [16], sICH occurred in $6.4 \%$ of alteplase-treated patients within $36 \mathrm{~h}$ of stroke onset, a significant increase compared to patients receiving placebo [16]. For over 14 years, the development and refinement of tPA has continued. In the most recent ECASS III trial [14], the incidence of ICH and sICH was higher with alteplase than with placebo $(27.0 \%$ vs. $17.6 \%, p=0.001$, and $2.4 \%$ vs. $0.2 \%, p=0.008$ ), respectively.
However, the mortality rate did not differ significantly between the alteplase and placebo groups $(7.7 \%$ and $8.4 \%$, respectively, $p=0.68$ ) and there was no significant difference in the rate of other serious adverse events. Thus, even though tPA is effective at causing partial or complete clot lyisis with an expanded therapeutic window, transient or permanent reocclusion was observed in about $35 \%$ of cases [16], and these patients typically exhibited worse clinical outcome than those with stable alteplase-induced recanalization.

In 1999, the Stroke Therapy Academic Industry Roundtable (STAIR) Committee [17] put forth recommendations for the effective development of new therapies of AIS. The report arbitrarily defined some of the animal models and methodologies that should be used to develop treatments, including the possible use of rats and primates. However, STAIR indicated that there are "currently there are no standardized, well-accepted models of stroke recovery in primates, although limited experience exists with baboons." As far as a primate model, STAIR also cites the use of squirrel monkeys, macaques, and marmosets. Indeed, marmosets were used during the development of NXY059 (Cerovive) by Astra-Zeneca, which led the most devastating failure of NXY-059 [18, 19]. Was failure of NXY-059 predictable based upon the pharmacological characteristics of NXY-059 and therapeutic window in preclinical stroke models? Yes, if one considers the chemical properties and pharmacological profile of NXY059 in preclinical studies.

Clearly, with only one effective FDA-approved stroke treatment and with the recent failure of a promising pharmacological therapeutic candidate, there remains a need to develop treatments for stroke. However, the question is how can the scientific community develop effective stroke treatment? Is there one or more preclinical animal models that can be used for effective translational research? This review will specifically focus on the scientific justification for the use of a rabbit embolic stroke model as a possible gold standard assay to develop thrombolytics, neuroprotective agents, and devices to treat AIS. Since reviews of other stroke models have already been documented in the scientific literature, the reader is referred to those reviews for more information [20-27].

\section{Translational Stroke Research}

Investigators in translational research seek to use a predictable animal model of AIS to develop an effective stroke therapy. In accordance with the original STAIR criteria and recommendations [17], a therapeutic agent being developed for the treatment of AIS should be tested in an animal model that mimics stroke in humans and uses functional recovery as an outcome measure because functional recovery is a major end point in clinical trials 
[17]. In AIS patients, a treatment is and can only be considered successful if it results in a favorable clinical outcome, an outcome primarily based upon motor functions and overall well-being evaluated using one of two standard clinical outcome measures: the National Institutes of Health Stroke Scale (NIHSS) and the modified Rankin Scale (mRS), both of which have been extensively reviewed in the literature [28-32].

Is there an animal model of embolic stroke that parallels stroke in patients? The answer is both yes and no! This year, 2010, is the silver (25th) anniversary of the rabbit small clot embolic stroke model (RSCEM) that was used to demonstrate that TPA could improve behavior or clinical rating scores [33] when administered following a stroke. There were also other reports using a rabbit embolic stroke model to study tPA pharmacology from Fisher and colleagues $[34,35]$. They showed that tPA induced partial or complete thrombus dissolution without the development of developed macroscopic cerebral hemorrhage. Moreover, Seibert and colleagues used a rabbit embolic stroke model to demonstrate that IPA can increase cerebral reperfusion and reduce infarct volume measured using the mitochondrial activity stain 2,3,5-triphenyltetrazolium chloride [36]. A similar result was also demonstrated by Gross et al. [37]. The RSCEM has been further characterized as a model where embolism using non-autologous clots leads to reduced cerebral blood flow, cell death, and decreased cortical energetics [38-40].

The original embolic stroke paper [33] described the embolization of awake unanesthetized rabbits in order to determine both the initial effects of embolization and the long-term effect of embolization on behavior. The absence of anesthesia is an advantage when conducting stroke research to parallel human stroke since many known anesthetics have "neuroprotective" activities that can confound scientific results [41-43].

The use of clinical rating scores (a behavioral end point) parallels some components of the mRS scale that is used for stroke patients, a common neurological end point in most clinical trials of ischemic stroke. Initially, the investigators used a three-tiered rating scale for behavioral analysis of embolized rabbits: normal, abnormal, or dead [33]. The original RSCEM paper describing the efficacy of tPA did not reveal the percentage of dead animals included in the study or whether tPA affected mortality. Nevertheless, to date, the RSCEM is still used, and the clinical scoring which predominantly measures motor function includes death as an outcome to parallel the death event that occurs in AIS clinical trials [44-47]. The inclusion of death may be important when designing preclinical stroke animal studies since death is an outcome measured in human studies (see NIHSS and mRS) [28-32]. For instance, in the original NINDS tPA clinical trial publication, even though mortality between groups was not significantly different, mortality at 3 months was $17 \%$ in the tPA group and $21 \%$ in the placebo group $(p=0.30)$ [16]. In the more recent ECASS publication, mortality was also not different between groups and only accounted for $7.7 \%$ of patients in the tPA group and $8.4 \%$ in the placebo group [14]. While there are clear differences between the mortality rates in the NINDS rtPA trial and the ECASS tPA trial, there were no differences in each of the individual trials. Indeed, the inclusion of mortality rate or death in rabbits may point to, at least in part, why the RSCEM was predictive of tPA efficacy in humans.

Even if one accepted standard behavioral measures short of death, the behaviors that predict drug and/or device efficacy in humans are largely unknown, and outcome measures in animal models are evaluated at short times following ischemia (1-21 days) and not at the times required for approval by the FDA in humans (3 months or more). The bottom line is that death as an end point is extremely useful and must be included as an outcome measure in animal models of stroke. This is in contrast to current practice for the majority of researchers conducting stroke research in models other than the RSCEM where early deaths are simply excluded from the experiment. This ultimately leads to skewed results and erroneous findings when final results are calculated based only upon surviving animals.

There has also been significant study of tPA using rodent models of embolic stroke. Table 1 documents some of the beneficial and detrimental effects of tPA by leading rodent stroke researchers. As is clearly evident from the literature, tPA is effective at reducing infarct volume in rodents following large clot embolic strokes and providing some behavioral improvement [48-53]. From the cited literature, it appears that tPA is beneficially effective in rodent between 2 and $4 \mathrm{~h}$ following a stroke and ineffective or detrimental thereafter [51]. The detrimental effects even include significantly increased infarct volume compared to the vehicle control group [53]. Moreover, in the rodent embolic stroke model, tPA produces significant hemorrhagic transformation, which is dependent upon both the dose and time of tPA administration [49-51]. The knowledge of the dosing and therapeutic window effects of tPA in rodent models comes from a survey of studies from multiple investigators since there are no comprehensive doseresponse and therapeutic window studies in rodent embolic stroke models that can be directly compared to the RSCEM studies described above. Nevertheless, tPA does save brain in rodents and improves behavior, but the dosing and timing relationships are unclear.

To summarize, tPA has a therapeutic window of $1-1.5 \mathrm{~h}$ in the RSCEM and an effective therapeutic window of $3-4.5 \mathrm{~h}$ in AIS patients. Thus, for this thrombolytic agent, the therapeutic window AIS/RSCEM ratio (ARR) is approximately 3 . 
Table 1 Correlative analysis of tPA effects in rodent embolic stroke models

\begin{tabular}{ll}
\hline Research group & Treatment time and pharmacological result \\
\hline Chopp [48, 100] & $1 \mathrm{~h}$ : decreased infarct volume \\
& $2 \mathrm{~h}$ : decreased infarct volume \\
& $4 \mathrm{~h}$ : increased BBB leakage, no behavioral improvement and no change in infarct volume \\
& $2 \mathrm{~h}$ : decreased infarct volume \\
Lo [49, 51] & $6 \mathrm{~h}$ : confluent hemorrhagic infarction and both infarction and neurological deficits were worsened by tPA \\
Fisher [101] & $3 \mathrm{~h}$ : hemorrhagic infarction type 2 hemorrhages \\
Overgaard [52, 53] & $15 \mathrm{~m}-2$ h: reduced the infarct volume and improved the clinical score when administered up to 2 h following stroke \\
& $4 \mathrm{~h}$ : prolonging the delay of treatment increased the infarct volume \\
\hline
\end{tabular}

\section{Rationale for Using the RSCEM as a Translational Stroke Model}

\section{Alteplase}

The NINDS Study [16] initially established that intravenous rtPA improved neurological outcome in approximately 160 patients out of 1,000 treated, preferably when given within $3 \mathrm{~h}$ of stroke onset. However, after $6 \mathrm{~h}$, alteplase was ineffective and neurological outcome was not different from that in the placebo group. Based upon this study, the FDA approved the use of alteplase in the USA for selected patients with AIS [16]. Follow-up studies further emphasized the need for rapid treatment with alteplase after AIS onset $[5,14,54-61]$. Recently, alteplase has been shown to be an effective stroke treatment up to $4.5 \mathrm{~h}$ after a stroke [14]. It is interesting to note that in patients who underwent intravenous alteplase therapy within 90 min of stroke onset, functional outcome at 3 months was excellent and was sustained for at least 12 months. Subsequent analysis confirmed that there is a time effect such that earlier treatment leads to greater likelihood of a beneficial effect [62]. In addition, in patients responding to IPA, the treatment proved to be cost-effective as there was reduced long-term hospitalization and improved rehabilitation [5, 54-61].

One of the unexpected successes of the initial NINDS tPA trial in human stroke was that tPA was effective not only for presumed cardioembolic stroke but also for presumed atheroembolic and small vessel lacunar stroke [16]. Indeed, the NINDS rtPA trial publication [16] indicated that $62 \%$ of subjects improved with tPA compared to $41.5 \%$ with placebo following lacunar stroke, and $38 \%$ of subjects improved with tPA compared to $29 \%$ with placebo following cardioembolic stroke [16]. These data did not provoke changes in thinking about the pathogenesis of different types of stroke and may have been deemphasized because of uncertainties about criteria for lacunar stroke. The efficacy of tPA in lacunar stroke likely had a role in accounting for the fact that infarct volume was not predictive of outcome in the NINDS tPA stroke trial [16]. Of note is that the increases of endogenous blood levels of TPA and PAI are similar in cardioembolic, thromboembolic, and lacunar stroke [63]. Finally, a recent study using standard TOAST criteria for the three major types of stroke examined 90 consecutive patients and demonstrated that the efficacy of tPA in cardioembolic, thromboembolic large vessel, and in lacunar stroke was comparable [64].

The importance of the role of tPA in large vessel thromboembolic stroke and small vessel lacunar stroke has not been addressed by either basic or clinical stroke scientists. On the clinical side, these data suggest that clot formation plays a key patho-etiological role in lacunar stroke and that in situ thrombosis associated with atheroembolic stroke may also be very important in stroke pathogenesis [65]. The efficacy of tPA in cardioembolic, large vessel atheroembolic and small vessel lacunar stroke has important implications for the predictive value of animal models of stroke. Though everyone agrees that embolism with an autologous clot likely mimics cardioembolic stroke fairly well, there is no accepted model with a well-defined clinically relevant behavioral end point that specifically mimics large vessel cardioembolic stroke in animals. However, since tPA improves outcome of all three of these stroke types in humans, an embolic animal model that represents any of the subtypes might be considered as a potential model to develop new treatments.

\section{Evaluation of Neuroprotective Agents}

Since only tPA has been approved by the FDA, the translational power of the RSCEM is relatively unknown, but there are numerous new data to support our contention that the RSCEM should be used for translational research. Recently, the free radical scavenger NXY-059 was tested in multiple clinical trials based upon significant efficacy in rodent and marmoset models of stroke [66-71]. The following section will evaluate the preclinical and clinical 
results obtained with the hydrophilic nitrone-free radical scavenger NXY-059 and compare them to hydrophobic free radical scavenger edaravone, a compound that is used in Japan to treat AIS.

\section{NXY-059}

Centaur Pharmaceuticals, Renovis Inc., and Astra-Zeneca Inc. attempted to develop disodium-[(tert-butylimino)methyl]benzene-1,3-disulfonate-N-oxide (NXY-059), a watersoluble lead nitrone [72]. The rationale for choosing this compound is not clear since the addition of two sulfonyl groups significantly reduced the ability of the drug to effectively cross the BBB [73, 74], thus limiting its activity outside of the vascular compartment [73].

The impetus for rapid development of NXY-059 was based upon Astra-Zeneca-supported preclinical evidence from rodent studies and a marmoset permanent MCAO stroke model (reviewed in $[6,75])$. In rats with transient focal ischemia produced by occlusion of the MCA, neuroprotection measured by improved behavioral scores could be observed if NXY-059 was administered up to $6 \mathrm{~h}$ following occlusion $[70,73]$. In the primate permanent MCA occlusion model, NXY-059 reduced spatial perception neglect and decreased gray and white matter damage [67], with a therapeutic window of $4 \mathrm{~h}$ when the drug was infused for 24-48 h. However, ischemia produced by invasive permanent occlusion of the MCA (i.e., method from Marshall et al. [66-68]: "After turning a large cranial flap and opening the dura over the right lateral frontal cortex, the right M1 segment of the MCA, $2 \mathrm{~mm}$ medial to the olfactory tract, was permanently occluded. The vessel was both occluded and bisected by electrocoagulation at this site") does not mimic the clinical presentation of embolic stroke.

To generate a better understanding of the potential of NXY-059 as a treatment, we used a more representative animal model of human embolic stroke. Using the RSCEM, generic NXY-059 (synthesized and validated at the VASDHS by Dr. Robert Purdy and identified as NXY$059 \mathrm{~g}$ ) was shown to reduce embolism-induced behavioral dysfunction when the drug was administered up to $1 \mathrm{~h}$ after the insult, but not thereafter $[44,76]$. Thus, there was a clear difference between the therapeutic window derived from the rodent/marmoset model (i.e., 4-6 h) vs. the embolic stroke model (i.e., 1 h). Nevertheless, even though these data were presented in the peer-reviewed literature during the early development of NXY-059, Astra-Zeneca Inc. and Renovis Inc. continued with the development of NXY-059 as described below. It is interesting to note that Bath et al. [75] recently stated that NXY-059 was neuroprotective in experimental stroke based upon 15 AstraZeneca-supported studies involving rats (544), mice [9], and marmosets [32], although "bias" may have resulted in efficacy being overestimated.

Phase III clinical trials, designated as the Stroke Acute Ischemic NXY-059 Treatment (SAINT I and II) conducted by Astra-Zeneca assessed the efficacy profiles of the investigational drug NXY-059 in stroke patients. In the first trial, 2,270 mg of NXY-059 was infused per hour, reduced after the first hour to $480-960 \mathrm{mg} / \mathrm{h}$ for $71 \mathrm{~h} \mathrm{[77]}$. The claim was made that a target concentration of 260 umol/1 was to be achieved. In the trial, 1,722 AIS patients received a 72-h infusion of placebo or NXY-059 within $6 \mathrm{~h}$ of stroke onset [77]. The primary outcome, defined as disability at 90 days and assessed according to the mRS $(p=0.038)$ for disability, was only slightly improved, but other outcome measures like neurological functioning measured by the NIHSS were not [77]. In the follow-up SAINT II trial, 1,588 patients were treated the same dosing regimen of NXY-059 that was used in SAINT 1 [19], and the inclusion criteria as far as time to treatment were the same. The mean time to treatment with NXY-059 was $3 \mathrm{~h}$ and $46 \mathrm{~min}$, similar to that of SAINT I [19, 77]. SAINT II showed that NXY-059 did not meet its primary outcome of a statistically significant reduction in strokerelated disability, as assessed by the $\mathrm{mRS}$ ( $p=0.33$, odds ratio of 0.94). Subgroup analyses, including time to treatment, did not demonstrate a treatment benefit. In addition, NXY-059 did not statistically significantly improve neurological status vs. placebo on the NIHSS $(p=0.70)$. The results of the SAINT II trial were disappointing, but not unexpected in light of the modest positive effect of NXY-059 in the SAINT I trial.

In both SAINT trials, time to treatment (approximately $4 \mathrm{~h}$ ) was well within the therapeutic window predicted by the stringent preclinical permanent occlusion rodent and marmoset model studies (approximately 4-6 h), but not that predicted by the RSCEM ( $1 \mathrm{~h}$, see Table 1$)$. Thus, it is likely that a combination of an inferior chemical compound, poor CNS distribution, and a short therapeutic window resulted in the lack of efficacy in over 3,400 AIS patients.

To summarize, NXY-059 $\mathrm{g}$ had a therapeutic window of $1 \mathrm{~h}$ in the RSCEM and no effective therapeutic window in AIS patients when tested with a time to treatment of $3.76 \mathrm{~h}$. Thus, for this hydrophilic agent, the therapeutic window ARR is 0 .

\section{Edaravone}

Unlike the hydrophilic molecule NXY-059 described above, Edaravone (3-methyl-1-phenyl-2-pyrazolin-5-one, Radicut, MCI-186) is a low-molecular-weight free radical scavenger that readily crosses the BBB [78, 79]. The preclinical experience with edaravone is quite extensive since it has been under development by Mitsubishi-Tokyo 
Pharmaceutical Inc. of Tokyo, Japan for over a decade [78, 79]. Like NXY-059, edaravone has the potential to scavenge free radicals, but its activity is not limited to the vascular compartment because of its hydrophobic properties.

In the RSCEM, edaravone administered subcutaneously decreased behavioral deficits for the treated population when administered 5 and 60 min post-embolization [47]. For the early post-embolization time to treatment, the behavioral increases were in the range of $94-195 \%$ over a standard vehicle control, in this case dimethylsolfoxide. More importantly, when edaravone was administered $3 \mathrm{~h}$ following embolization, there was still a significant increase in behavior, but edaravone was inactive when applied $6 \mathrm{~h}$ following embolization. The study using the RSCEM indicates that edaravone may have substantial therapeutic benefit for the treatment of AIS, and the drug had a therapeutic widow of at least $3 \mathrm{~h}$ in rabbits.

The use of edaravone to treat stroke remains controversial, mainly because there have not been randomized double blind international trials to support the use of the drug. That point is duly acknowledged, however, based upon Japanese clinical trials in stroke patients. MitsubishiTokyo Pharmaceutical Inc. (Tokyo, Japan) has obtained approval from the regulatory agency in Japan for the treatment of AIS patients with edaravone if the drug was administered within $72 \mathrm{~h}$ of the ischemic event [78-83]. Suda et al. [84] have proposed that edaravone, when given within 3-6 h of a cardioembolic stroke, can salvage the boundary zone of the infarct in patients (i.e., ischemic penumbra) and reduce the extent of edema, presumably resulting in clinical improvement. Yoshifumi [85] reported preliminary findings of a clinical trial showing that patients treated with edaravone prior to administration of intravenous tPA had a reduced incidence of hemorrhage compared to tPA-treated patients [85]. Thus, the Japanese experience with edaravone suggests that the drug is superior, in many ways, to the failed Astra-Zeneca spin trap agent NXY-059 $[19,86]$. Nevertheless, outside of Japan, there has been little interest in the clinical development of edaravone for the treatment of AIS.

In a 2009 study by Sinha et al. [87], the first Indian experience with edaravone was published. Twenty-two AIS patients were given $30 \mathrm{mg}$ of edaravone twice daily for 14 days by infusion. The mean time to treatment following onset was $26.5 \pm 21.27 \mathrm{~h}$. The study used mRS and Barthel index (BI) measured up to 90 days following treatment. In the study, $68 \%$ of patients had a favorable outcome where the mean mRS score decreased from $4.01 \pm 0.92$ at baseline to $1.86 \pm 1.07$ at day $90 \quad(p<0.005)$, and the mean BI increased from $40.00 \pm 30.11$ at baseline to $75.62 \pm 22.86$ at day $90(p<0.005)$. This was the first confirmation that edaravone had efficacy in patients and that the effect could be observed with a long therapy.
Although edaravone is purported to have significant benefit in stroke patients, there may be an increased risk of renal toxicity associated with its administration [88]. It has been reported that approximately $45 \%$ of patients with edaravone-induced renal toxicity recover renal function after edaravone treatment is stopped [88]. This toxicity was not observed by Sinha et al. [87].

The current therapeutic window information for edaravone from the RSCEM [47] appears to be at odds with the current clinical trial information which suggests that edaravone may be used 24-72 $\mathrm{h}$ following a stroke [78-83]. In contrast to the original trial report where a significant difference between edaravone-treated and placebo-treated groups measured using the mRS $(p=0.0382)$ was reported, Inatomi et al. [82] showed that edaravone could only produce a modest clinical improvement in AIS patients, with NIHSS $\leq 7$, efficacy that was not seen in the moderate to severe AIS patients (NIHSS > 7). Moreover, the authors report that 6 months after AIS onset, patients who became independent $(\mathrm{mRS}<2)$ were more likely to have received edaravone than placebo ( $41 \%$ vs. $28 \%, p=0.066)$. Since the results from Sinha et al. [87] are positive and promising, it appears that edaravone may have some utility in the treatment of AIS, but additional fully randomized clinical trials are essential for FDA approval of this free radical scavenger.

To summarize, edaravone has a therapeutic window of $3 \mathrm{~h}$ in the RSCEM and an effective therapeutic window of 24-72 $\mathrm{h}$ in AIS patients. Thus, for this hydrophobic agent, the therapeutic window ARR is $8-24$.

\section{Transcranial Near-Infrared Laser Therapy}

A growing body of scientific literature exists documenting the photo-biostimulation effects of infrared laser therapy both in vitro and in vivo [89-91]. Recently, irradiation with specific infrared wavelengths that penetrate deep into the brain [90] was shown to stimulate adenosine triphosphate (ATP) formation by mitochondria, an effect thought to be mediated by the mitochondrial chromophore cytochrome $\mathrm{c}$ oxidase [39]. The overall result of laser treatment is postulated to induce improved energy metabolism and, potentially, enhanced cell viability. See the review by Lapchak et al. [40] for a detailed discussion of nearinfrared laser irradiation therapy (NILT) safety, efficacy, and mechanism of action.

In the RSCEM, transcranial NILT was shown to be safe and promoted significant behavioral improvement if treatment was initiated up to $6 \mathrm{~h}$ following embolization [46]. Moreover, the effect of NILT was durable and improvements in behavior could be still measured 21 days after embolization and a single treatment. Therefore, on the basis of the results with the RSCEM, we concluded that NILT 
should be developed as a new treatment for patients with AIS. The main advantage to develop NILT is the long therapeutic window in the RSCEM. We have recently shown that NILT treatment can significantly increase cortical ATP content in embolized rabbits [39, 40], suggesting that NILT-induced behavioral improvement may be related to improved mitochondrial function.

Subsequently, a number of studies using the rat MCA occlusion model sponsored by PhotoThera Inc. (Carlsbad, CA, USA) have been published $[89,91]$. In contrast to the results in the RSCEM in which laser irradiation promoted significant neuroprotection when applied up to $6 \mathrm{~h}$ postembolization [46, 92] and a non-significant improvement when applied $12 \mathrm{~h}$ following embolization [46], in the rat MCAO model, laser treatment was only effective when applied $24 \mathrm{~h}$, but not $4 \mathrm{~h}$ or less, after stroke onset $[89,91]$. The positive results documented for NILT in animal models of stroke, especially the long therapeutic window in the RSCEM (Table 2), prompted the rapid initiation of the Neurothera Effectiveness and Safety trial (NEST-I), a prospective, intent-to-treat, multicenter, international, double-blinded trial sponsored by PhotoThera Inc. [93]. The preliminary results from 120 AIS patients with a treatment time of 2-24 h (median time $18 \mathrm{~h}$ ) showed that more patients in the laser-treated group had successful outcomes from baseline to 90 days, measured by a mean change in the NIHSS and mRS, than did controls $(p=0.035$, stratified by severity and time to treatment; $p=0.048$, stratified by severity alone). Based upon the promising results of the NEST-I trial, the NEST-2 trial, a double-blind, placebo (sham) controlled trial was initiated in 57 centers in four countries [94]. In the trial, 337 patients were randomized to the NILT group and 327 to the sham group. For NEST-2, the time to treatment was $14.6 \pm 5.9$ and $14.7 \pm$ $6.1 \mathrm{~h}$ for the NILT and sham groups, respectively, with a maximum time to treatment of $23.9 \mathrm{~h}$ in each group. Unlike NEST-1 where the NIHSS and mRS scales were used for efficacy assessment, NEST-2 used mRS as the primary end point and subsequently NIHSS was used for post hoc analysis. Using $\mathrm{mRS}$, the primary efficacy end point was a favorable 90-day score of 0 to 2 assessed by the modified Rankin Scale. One hundred and twenty patients (36.3\%) in the NILT group achieved favorable outcome vs. 101 $(30.9 \%)$ in the sham-treated group $(p=0.094$, odds ratio $1.38,95 \%$ CI $0.95-2.00)$. When viewed to include all patients enrolled in each treatment group, there was no overall significant effect of NILT; however, with the numbers enrolled in each group, the study may have been underpowered. However, a post hoc analysis of patients with a baseline NIHSS of $<16$ showed a favorable outcome at 90 days on the primary end point $(p<0.044)$. It is interesting to note that the authors documented a mean NIHSS score of $13.1 \pm 4.7$ and $13.2 \pm 4.6$, respectively, for the NILT and sham-treated groups, which is well within the range of the specific group (i.e., NIHSS $<16$ ) shown to have significant behavioral improvement when the post hoc test was done. Clearly, NILT does have a physiological effect in AIS patients, and there is a long therapeutic window of opportunity for treatment (approx. 14-24 h). However, it is possible that not all patients will respond to this novel form of treatment when applied as a monotherapy.

To summarize, NILT has a therapeutic window of $6 \mathrm{~h}$ in the RSCEM and an effective therapeutic window of (mean time to treatment from NEST-2) of $14.6 \mathrm{~h}$ in AIS patients. Thus, for this novel method of neuroprotection, the therapeutic window ARR is 2.43 .

\section{Model Hypothesis Testing}

Based upon the above preclinical and clinical studies with different classes of treatments including an FDA-approved thrombolytic, free radical scavengers and a laser device, we hypothesize that the RSCEM can be used as an effective translational tool to develop new stroke treatment. It is

Table 2 Correlative analysis: RSCEM vs. AIS patients

\begin{tabular}{llll}
\hline Therapy & Effect in RSCEM & Effect in AIS patients ${ }^{\mathrm{b}}$ & TW (AIS/rabbit) ARR \\
\hline tPA & $\begin{array}{l}\text { Improved behavior [33, 45] } \\
\text { Therapeutic window 1-1.5 } \mathrm{h}\end{array}$ & $\begin{array}{l}\text { Improved clinical scores } \\
\text { Therapeutic window 3-4.5 h, [14, 16, 95] }\end{array}$ & $3-4.5 / 1-1.5$ ARR 3 \\
NXY-059 & $\begin{array}{l}\text { Improved behavior [44, 76] } \\
\text { Therapeutic window 1 } \mathrm{h}\end{array}$ & No effect when administered within a TT of 3.76 h of a stroke [19, 77] & No efficacy/1 ARR 0 \\
Edaravone & $\begin{array}{l}\text { Improved behavior [47] } \\
\text { Therapeutic window 3 h }\end{array}$ & $\begin{array}{l}\text { Improved clinical scores } \\
\text { Therapeutic window 24-72 hours [78-83, 87] }\end{array}$ & 24-72/3 ARR 8-24 \\
NILT & $\begin{array}{l}\text { Improved behavior [46] } \\
\text { Therapeutic window 6 h }\end{array}$ & $\begin{array}{l}\text { Improved clinical scores with caveat of patients having an NIHSS }<16 \\
\text { Therapeutic window TT 14.6 h [94] }\end{array}$ & 14.6/6 ARR 2.43
\end{tabular}

$T T$ time to treatment, $T W$ therapeutic window, ARR AIS/RSCEM ratio

${ }^{a}$ RSCEM end point—behavior using the analysis using quantal analysis

${ }^{\mathrm{b}}$ AIS patient endpoint—clinical rating scores using NIHSS and/or mRS 
important to emphasize that at this particular point in the development of stroke treatments, we are hypothesizing that the RSCEM is useful for incrementally advancing the translational development of treatments. However, it is essential that the more common rodent models widely used by the majority of stroke researchers should continue to be used for initial drug screening and for the study of mechanisms following stroke insults.

For translational drug development purposes, the FDAapproved drug tPA is the current standard to which all other treatments must be compared. If one were comparing two thrombolytics, one would require that the test thrombolytic be equally efficacious or more so than TPA in the RSCEM. Not only should the new thrombolytic be efficacious, it should also have a therapeutic window equivalent to or longer than the original compound. This same logic should also apply to non-thrombolytic "neuroprotectants" and other novel forms of AIS therapy. That is, the behavioral improvement observed with TPA in the RSCEM must be matched by any proposed "therapy" in order for one to predict that the drug will be useful in human stroke. The logic is the following: the thrombolytic protects tissue by opening up closed vessels, and this appears to be independent of clot source based upon the NINDS tPA trial [16]. The "therapy" supports cell survival in the presence or absence of thrombolysis, and the degree of behavioral improvement must be equivalent to or better than that observed with tPA in order for an effect on behavior to be observed in humans with stroke. If the behavioral outcome of a new "therapy" is inferior to the behavioral outcome of tPA in the RSCEM, it probably will not be a successful treatment in human stroke. Stated another way, if the behavioral improvement (i.e., neuroprotection obtained without reperfusion) is similar to or better than the improved behavioral outcome obtained with thrombolysis with tPA, then this new "therapy" likely could show significant clinical benefit in human stroke.

The approach just mentioned stands in marked contrast to the majority of stroke studies performed in animals. In most animal studies, a "therapy" is compared to a "saline or vehicle control," and almost every animal study reports a statistically significant positive result based upon decreased infarct volume and/or behavioral improvement on an arbitrary behavioral scale. However, there is no way to know how these results translate to improving behavioral outcomes in human stroke victims. Indeed, the only known paradigm is tPA treatment in the RSCEM because the model was used to develop tPA. A rational strategy for assessing new therapies in the future should include a comparison of therapy and vehicle in the RSCEM that also includes tPA treatment in both groups. If it can be demonstrated that the new therapy has a longer therapeutic window than tPA and if the therapy improved behavior, then the clinical design may include combination therapy and additional groups of patients with therapy alone as long as the combination would not be contraindicated (i.e., the new therapy would have detrimental effects in combination with tPA or in some way inhibit the activity of tPA).

\section{A Model Basis for Effective Translation}

Translating results of experimental stroke treatments from the laboratory bench to the patient's bedside has proven difficult. In the RSCEM, tPA effectively improved scores when given 1-1.5 $\mathrm{h}$ following embolization, and in patients, the therapeutic window is along the order of $3-4.5 \mathrm{~h}$ after stroke onset for a thrombolytic that increases cerebral perfusion [14, 16, 95]. By inference, it was judged that the differential between the observed time of effectiveness in the model and in patients would be two to threefold [95]. That is, when drugs have a therapeutic window of $1 \mathrm{~h}$ in embolized rabbits, a window of 2-3 h would be expected in stroke patients. Consistent with this, in the RSCEM, edaravone is effective up to $3 \mathrm{~h}$ following embolization [47] and has now been shown at multiple clinical sites to be effective when given 24-72 h after a stroke [82, 83, 87, 96]. Moreover, in the RSCEM, laser irradiation was effective up to $6 \mathrm{~h}$ following a stroke [46], and as predicted by the model, the NEST-I trial [93] found that laser therapy improved clinical rating scores if patients were treated within $24 \mathrm{~h}$ following a stroke. In addition, the NEST-2 trial provided additional evidence that laser therapy could be used effectively with a mean time to treatment of $14 \mathrm{~h}$ [94] if the correct population of patients is studied.

The results from the preclinical and clinical development of the different types of stroke treatment described above suggest that success can be achieved if an optimal preclinical model is used to develop the new treatment and if the treatment is compared to an FDA-approved standard of care. The correlative data presented suggest that there is a distinct relationship between the therapeutic window that can be achieved in the RSCEM and a window of opportunity to treat in AIS patients. The correlation may depend somewhat upon the type of treatment being translated from animal to human whether it be pharmaceutical or device-derived. The data have been consolidated in Table 2 and presented in two columns for direct comparison. Based upon 2 of the comparisons, the ARR is 2.43-3. This indicates that a treatment that is effective at $1 \mathrm{~h}$ in the RSCEM would be effective up to $3 \mathrm{~h}$ in AIS patients. Of course, the data for edaravone are outliers to this hypothesis that cannot be easily explained. For edaravone, the current ARR is $8-24$, which appears anomalous for the following reason. If we use the minimum ratio of 8 and take into consideration that NXY-059 was effective for $1 \mathrm{~h}$ following 
embolization in the RSCEM $[44,76]$, then NXY-059 would have been predicted to be effective with a time to treatment of $8 \mathrm{~h}$ in the SAINT II trial [19]. If we consider the ARR correlation of 2.43-3 resulting from the NINDS tPA and NEST trial, then the maximum efficacy window for NXY059 predicted by the RSCEM would be in the range of 2.43-3 [44, 76]. The fact that mean time to treatment for NXY-059 used in the SAINT trial was $3.6 \mathrm{~h}$ would suggest that NXY-059 would have been ineffective in AIS patients based upon the RSCEM ratio. Indeed, NXY-059 failed in the SAINT-2 trial [19].

The RSCEM has typically used 2- to 3-month-old male rabbits as a screen for therapeutic efficacy measuring behavior (primarily motor function) 1 or 2 days postembolization [44, 45, 76] and in the one study up to 21 days post-embolization [40,46]. Even though there is strong correlative data between the behavioral outcome measured in rabbits (2-21 days post-stroke) and humans (90 days) post stroke, there is a need to address long-term outcomes in all preclinical models if they are to be used as effective translational tools. The RSCEM has been useful to predict "neuroprotective" treatment strategies administered within 1-6 h of embolization. However, if a drug or novel therapy targeting recovery of function is to be developed, then behavioral monitoring times should be extended past 21 days to ascertain the effects of the treatments on functional recovery.

\section{Rabbit and Human Brain Differences}

Besides the obvious anatomical feature differences between the brain of the two species, which include differences in size, shape, cortical folding, and gray/white matter ratios, the exact reasons for the different therapeutic windows between rabbit and man are not clearly understood. However, the recent article by Karbowski [97] sheds significant light on metabolic differences between the two species when measured under normal conditions. In New Zealand white rabbits, the basal metabolic rate (BMR) is approximately $750 \mathrm{kcal} \mathrm{m}^{-2}$ day $^{-1}$ [98], whereas the basal rate in human is $720 \mathrm{kcal} \mathrm{m}^{-2} \mathrm{day}^{-1}$ [99], a human/rabbit ratio of 0.96 . The BMR data for both species take into consideration the "surface area law" about the "constant" relationship between basal metabolic rate and surface area [99]. It has been reported that total basal cerebral metabolism rate (BCM) in human brain (average brain weight $1,300 \mathrm{~g}$ ) [97] is approximately 2.5 -fold that of rabbit brain (average brain weight $12 \mathrm{~g}$ ) [97] and that there is higher metabolism in gray matter compared to white matter [97]. Karbowski [97] also states that "cerebral energy use increases more steeply with brain size" than does BMR, and this is evident with a BMR of 0.96 compared to a BCM of 2.5. Thus, even though the BMR is similar between rabbits and humans, there is a large difference in $\mathrm{BCM}$ between the two species. The observation and/or correlation that the ARR provided above is $2.43-3$ and that the BCM is approximately 2.5 suggests that the differential therapeutic windows in the two species is in some way related to cerebral energy metabolism. When BCM is taken into consideration and ARR is expressed as ARR/BCM, the correlation is $0.97-1.2$. Thus, the correlative data suggest that the ARR may in some way be related to cerebral metabolism or energy utilization in the two species. Overall, this review establishes a basis in order to move a drug forward into a clinical trial, with the hopes of achieving a statistically significant improvement in mRS or NIHSS.

\section{Summary and Conclusions}

It is clear from the last 30 years of stroke research that there are no easy fixes for ischemic brain damage. At the present time, the RSCEM appears to be a useful predictor of positive outcome in stroke clinical trials when using NIHSS or mRS as the main clinical end point. Needless to say, the correlations hypothesized in this review of the RSCEM are based upon three positive treatments, one of which is FDAapproved, one of which is approved by the Japanese government, and one novel treatment which will continue to be scrutinized in the NEST-3 phase III clinical trial to be initiated later in 2010. The short $1 \mathrm{~h}$ therapeutic window for the failed spin trap agent treatment NXY-059 also lends credence to the proposed hypothesis that the RSCEM could be used as an effective screen during the translational research process to determine if compounds should be further developed or whether they should be abandoned.

Based upon the scientific justification presented in this review, we hypothesize that the RSCEM should be used as a potential "gold standard" model and translational tool in order to gauge the clinical potential of new treatments so that effective clinical trials can be developed to promote recovery of function and improve the well-being of AIS patients.

If time is brain, then the therapeutic window derived from saving rabbit brain following embolic strokes could assist with preventing human brain death.

Acknowledgments This article was supported by an NINDS Translational Research Grant U01 NS60685-01 to PAL. PAL is a Fellow of the American Heart Association (FAHA) and Director of Translational Research at Cedars-Sinai Medical Center. PAL is grateful to Dr. Patrick D. Lyden (Cedars-Sinai Medical Center, Department of Neurology, Los Angeles, CA), Luis de Taboada (Photothera Inc, Carlsbad, CA), and Dr. Frank Sharp (M.I.N.D. Institute and University of California at Davis, Department of Neurology) for suggestions and/ or for critically reviewing this article. Dr. Frank Sharp is thanked for coining the term "gold standard" for the RSCEM.

Conflict of Interest Disclosure PAL has no conflicts of interest to disclose and was not paid by any company to write this review article. 
Open Access This article is distributed under the terms of the Creative Commons Attribution Noncommercial License which permits any noncommercial use, distribution, and reproduction in any medium, provided the original author(s) and source are credited.

\section{References}

1. Ingall T (2004) Stroke-incidence, mortality, morbidity and risk. J Insur Med 36(2):143-152

2. Lloyd-Jones D, Adams R, Carnethon M, De Simone G, Ferguson TB, Flegal K et al (2009) Heart disease and stroke statistics - 2009 update: a report from the American Heart Association Statistics Committee and Stroke Statistics Subcommittee. Circulation 119(3):480-486

3. Petty GW, Brown RD Jr, Whisnant JP, Sicks JD, O'Fallon WM, Wiebers DO (2000) Ischemic stroke subtypes: a populationbased study of functional outcome, survival, and recurrence. Stroke 31(5):1062-1068

4. Petty GW, Brown RD Jr, Whisnant JP, Sicks JD, O'Fallon WM, Wiebers DO (1999) Ischemic stroke subtypes: a population-based study of incidence and risk factors. Stroke 30(12):2513-2516

5. Lapchak PA (2002) Development of thrombolytic therapy for stroke: a perspective. Expert Opin Investig Drugs 11(11):16231632

6. Lapchak PA, Araujo DM (2007) Advances in ischemic stroke treatment: neuroprotective and combination therapies. Expert Opin Emerg Drugs 12(1):97-112

7. Dirnagl U, Iadecola C, Moskowitz MA (1999) Pathobiology of ischaemic stroke: an integrated view. Trends Neurosci 22 (9):391-397

8. Michel P, Bogousslavsky J (2005) Penumbra is brain: no excuse not to perfuse. Ann Neurol 58(5):661-663

9. Moustafa RR, Baron JC (2006) Imaging the penumbra in acute stroke. Curr Atheroscler Rep 8(4):281-289

10. Fisher M (2004) The ischemic penumbra: identification, evolution and treatment concepts. Cerebrovasc Dis 17:1-6

11. Schellinger PD, Fiebach JB, Mohr A, Ringleb PA, Jansen O, Hacke W (2001) Thrombolytic therapy for ischemic stroke-a review. Part II-Intra-arterial thrombolysis, vertebrobasilar stroke, phase IV trials, and stroke imaging. Crit Care Med 29 (9):1819-1825

12. Schellinger PD, Fiebach JB, Mohr A, Ringleb PA, Jansen O, Hacke W (2001) Thrombolytic therapy for ischemic stroke-a review. Part I-Intravenous thrombolysis. Crit Care Med 29 (9):1812-1818

13. Verstraete M (1999) Newer thrombolytic agents. Ann Acad Med Singapore 28(3):424-433

14. Hacke W, Kaste M, Bluhmki E, Brozman M, Davalos A, Guidetti D et al (2008) Thrombolysis with alteplase 3 to 4.5 hours after acute ischemic stroke. N Engl J Med 359 (13):1317-1329

15. Lansberg MG, Bluhmki E, Thijs VN (2009) Efficacy and safety of tissue plasminogen activator 3 to 4.5 hours after acute ischemic stroke: a metaanalysis. Stroke 40(7):2438-2441

16. The National Institute of Neurological Disorders and Stroke rtPA Stroke Study Group (1995) Tissue plasminogen activator for acute ischemic stroke. N Engl J Med 333(24):1581-1587

17. No authors listed (1999) Recommendations for standards regarding preclinical neuroprotective and restorative drug development. Stroke 30(12):2752-2758

18. Ginsberg MD (2007) Life after cerovive: a personal perspective on ischemic neuroprotection in the post-NXY-059 era. Stroke 38 (6):1967-1972
19. Shuaib A, Lees KR, Lyden P, Grotta J, Davalos A, Davis SM et al (2007) NXY-059 for the treatment of acute ischemic stroke. N Engl J Med 357(6):562-571

20. Bailey EL, McCulloch J, Sudlow C, Wardlaw JM (2009) Potential animal models of lacunar stroke: a systematic review. Stroke 40(6):e451-e458

21. Prieto-Arribas R, Moreno-Gutierrez A, Simal-Hernandez P, Pascual-Garvi JM, Matias-Guiu J, Roda JM et al (2008) Experimental models of cerebral ischemia. Rev Neurol 47 (8):414-426

22. Feuerstein GZ, Zaleska MM, Krams M, Wang X, Day M, Rutkowski JL et al (2008) Missing steps in the STAIR case: a Translational Medicine perspective on the development of NXY059 for treatment of acute ischemic stroke. J Cereb Blood Flow Metab 28(1):217-219

23. Durukan A, Tatlisumak T (2007) Acute ischemic stroke: overview of major experimental rodent models, pathophysiology, and therapy of focal cerebral ischemia. Pharmacol Biochem Behav 87(1):179-197

24. Hua R, Walz W (2006) The need for animal models in smallvessel brain disease. Crit Rev Neurobiol 18(1-2):5-11

25. Carmichael ST (2005) Rodent models of focal stroke: size, mechanism, and purpose. NeuroRx 2(3):396-409

26. Fukuda S, del Zoppo GJ (2003) Models of focal cerebral ischemia in the nonhuman primate. ILAR J 44(2):96-104

27. Traystman RJ (2003) Animal models of focal and global cerebral ischemia. ILAR J 44(2):85-95

28. Lyden P, Lu M, Jackson C, Marler J, Kothari R, Brott T et al (1999) Underlying structure of the national institutes of health stroke scale: results of a factor analysis. Stroke 30:2347

29. Lyden P, Raman R, Liu L, Grotta J, Broderick J, Olson S et al (2005) NIHSS training and certification using a new digital video disk is reliable. Stroke 36(11):2446-2449

30. Sulter G, Steen C, De Keyser J (1999) Use of the Barthel Index and modified Rankin Scale in acute stroke trials. Stroke 30:1538

31. Wilson JT, Hareendran A, Grant M, Baird T, Schultz UGR, Muir $\mathrm{KW}$ et al (2002) Improving the assessment of outcomes in strokes. Stroke 33:2243

32. Young FB, Lees KR, Weir CJ (2003) Strengthening acute stroke trials through optimal use of disability end points. Stroke 34 (11):2676-2680

33. Zivin JA, Fisher M, DeGirolami U, Hemenway CC, Stashak JA (1985) Tissue plasminogen activator reduces neurological damage after cerebral embolism. Science 230(4731):1289

34. Phillips DA, Davis MA, Fisher M (1988) Selective embolization and clot dissolution with tPA in the internal carotid artery circulation of the rabbit. AJNR Am J Neuroradiol 9(5):899-902

35. Phillips DA, Fisher M, Smith TW, Davis MA (1988) The safety and angiographic efficacy of tissue plasminogen activator in a cerebral embolization model. Ann Neurol 23(4):391-394

36. Chehrazi BB, Seibert JA, Kissel P, Hein L, Brock JM (1989) Evaluation of recombinant tissue plasminogen activator in embolic stroke. Neurosurgery 24(3):355-360

37. Gross CE, Raymond SJ, Howard DB, Bednar MM (1995) Delayed tissue-plasminogen activator therapy in a rabbit model of thromboembolic stroke. Neurosurgery 36(6):1172-1177

38. Lapchak PA (2009) Effect of internal carotid artery reperfusion in combination with Tenecteplase on clinical scores and hemorrhage in a rabbit embolic stroke model. Brain Res 1294:211-217

39. Lapchak PA, De Taboada L (2010) Transcranial near infrared laser treatment (NILT) increases cortical adenosine-5'-triphosphate (ATP) content following embolic strokes in rabbits. Brain Res 1306:100-105

40. Lapchak PA, Streeter J, De Taboada L (2010) Transcranial near infrared laser therapy (NILT) to treat acute ischemic stroke: a 
review of efficacy, safety and possible mechanism of action derived from rabbit embolic stroke studies. Proc SPIE 7552:75520R

41. Matchett GA, Allard MW, Martin RD, Zhang JH (2009) Neuroprotective effect of volatile anesthetic agents: molecular mechanisms. Neurol Res 31(2):128-134

42. Kawaguchi M, Furuya H, Patel PM (2005) Neuroprotective effects of anesthetic agents. J Anesth 19(2):150-156

43. Koerner IP, Brambrink AM (2006) Brain protection by anesthetic agents. Curr Opin Anaesthesiol 19(5):481-486

44. Lapchak PA, Araujo DM, Song D, Wei J, Zivin JA (2002) Neuroprotective effects of the spin trap agent disodium-[(tertbutylimino)methyl]benzene-1,3-disulfonate $\mathrm{N}$-oxide (generic NXY-059) in a rabbit small clot embolic stroke model: combination studies with the thrombolytic tissue plasminogen activator. Stroke 33(5):1411-1415

45. Lapchak PA, Araujo DM, Zivin JA (2004) Comparison of Tenecteplase with Alteplase on clinical rating scores following small clot embolic strokes in rabbits. Exp Neurol 185(1):154-159

46. Lapchak PA, Wei J, Zivin JA (2004) Transcranial infrared laser therapy improves clinical rating scores after embolic strokes in rabbits. Stroke 35(8):1985-1988

47. Lapchak PA, Zivin JA (2009) The lipophilic multifunctional antioxidant edaravone (radicut) improves behavior following embolic strokes in rabbits: a combination therapy study with tissue plasminogen activator. Exp Neurol 215(1):95-100

48. Zhang L, Zhang ZG, Zhang RL, Lu M, Adams J, Elliott PJ et al (2001) Postischemic (6-hour) treatment with recombinant human tissue plasminogen activator and proteasome inhibitor PS-519 reduces infarction in a rat model of embolic focal cerebral ischemia. Stroke 32(12):2926-2931

49. Asahi M, Asahi K, Wang X, Lo EH (2000) Reduction of tissue plasminogen activator-induced hemorrhage and brain injury by free radical spin trapping after embolic focal cerebral ischemia in rats. J Cereb Blood Flow Metab 20(3):452-457

50. Kano T, Harada T, Katayama Y (2005) Attenuation of extravasation of tissue plasminogen activator by the free radical scavenger, edaravone: evaluation in a rat thromboembolic stroke model. Neurol Res 27(5):499-502

51. Kano T, Katayama Y, Tejima E, Lo EH (2000) Hemorrhagic transformation after fibrinolytic therapy with tissue plasminogen activator in a rat thromboembolic model of stroke. Brain Res 854 (1-2):245-248

52. Meden P, Overgaard K, Pedersen H, Boysen G (1994) Effect of hypothermia and delayed thrombolysis in a rat embolic stroke model. Acta Neurol Scand 90(2):91-98

53. Overgaard K, Sereghy T, Pedersen H, Boysen G (1994) Effect of delayed thrombolysis with rt-PA in a rat embolic stroke model. J Cereb Blood Flow Metab 14(3):472-477

54. Albers GW, Bates VE, Clark WM, Bell R, Verro P, Hamilton SA (2000) Intravenous tissue-type plasminogen activator for treatment of acute stroke: the Standard Treatment with Alteplase to Reverse Stroke (STARS) Study. Jama 283(9):1145-1150

55. Alberts MJ (1998) tPA in acute ischemic stroke: United States experience and issues for the future. Neurology 51(3 Suppl 3): S53-S55

56. Christou I, Alexandrov AV, Burgin WS, Wojner AW, Felberg RA, Malkoff M et al (2000) Timing of recanalization after tissue plasminogen activator therapy determined by transcranial Doppler correlates with clinical recovery from ischemic stroke. Stroke 31(8): $1812-1816$

57. Clark WM, Albers GW, Madden KP, Hamilton S (2000) The rtPA (alteplase) 0- to 6-hour acute stroke trial, part A (A0276g): results of a double-blind, placebo-controlled, multicenter study. Thromblytic therapy in acute ischemic stroke study investigators. Stroke 31(4):811-816
58. Grotta JC, Alexandrov AV (1998) tPA-associated reperfusion after acute stroke demonstrated by SPECT. Stroke 29(2):429 432

59. Grotta JC, Burgin WS, El-Mitwalli A, Long M, Campbell M, Morgenstern LB et al (2001) Intravenous tissue-type plasminogen activator therapy for ischemic stroke: Houston experience 1996 to 2000. Arch Neurol 58(12):2009-2013

60. Hacke W, Brott T, Caplan L, Meier D, Fieschi C, von Kummer R et al (1999) Thrombolysis in acute ischemic stroke: controlled trials and clinical experience. Neurology 53(7):S3-S14

61. Hacke W, Kaste M, Fieschi C, Toni D, Lesaffre E, von Kummer $R$ et al (1995) Intravenous thrombolysis with recombinant tissue plasminogen activator for acute hemispheric stroke. The European Cooperative Acute Stroke Study (ECASS). Jama 274 (13): 1017-1025

62. Marler JR, Tilley BC, Lu M, Brott TG, Lyden PC, Grotta JC et al (2000) Early stroke treatment associated with better outcome: the NINDS rt-PA Stroke Study. Neurology 55(11):1649-1655

63. Zunker P, Schick A, Padro T, Kienast J, Phillips A, Ringelstein EB (1999) Tissue plasminogen activator and plasminogen activator inhibitor in patients with acute ischemic stroke: relation to stroke etiology. Neurol Res 21(8):727-732

64. Hsia AW, Sachdev HS, Tomlinson J, Hamilton SA, Tong DC (2003) Efficacy of IV tissue plasminogen activator in acute stroke: does stroke subtyp really matter? Neurology 61:71-75

65. del Zoppo G (1988) Thrombolytic therapy in cerebrovascular disease. Curr Concepts Cerebrovasc Dis 23:7

66. Marshall JW, Cummings RM, Bowes LJ, Ridley RM, Green AR (2003) Functional and histological evidence for the protective effect of NXY-059 in a primate model of stroke when given 4 hours after occlusion. Stroke 34(9):2228-2233

67. Marshall JW, Duffin KJ, Green AR, Ridley RM (2001) NXY059, a free radical-trapping agent, substantially lessens the functional disability resulting from cerebral ischemia in a primate species. Stroke 32(1):190-198

68. Marshall JW, Green AR, Ridley RM (2003) Comparison of the neuroprotective effect of clomethiazole, AR-R15896AR and NXY-059 in a primate model of stroke using histological and behavioural measures. Brain Res 972(1-2):119-126

69. Peeling J, Del Bigio MR, Corbett D, Green AR, Jackson DM (2001) Efficacy of disodium 4-[(tert-butylimino)methyl]benzene-1,3-disulfonate $\mathrm{N}$-oxide (NXY-059), a free radical trapping agent, in a rat model of hemorrhagic stroke. Neuropharmacology 40(3):433-439

70. Sydserff SG, Borelli AR, Green AR, Cross AJ (2002) Effect of NXY-059 on infarct volume after transient or permanent middle cerebral artery occlusion in the rat; studies on dose, plasma concentration and therapeutic time window. Br J Pharmacol 135 (1):103-112

71. Zhao Z, Cheng M, Maples KR, Ma JY, Buchan AM (2001) NXY-059, a novel free radical trapping compound, reduces cortical infarction after permanent focal cerebral ischemia in the rat. Brain Res 909(1-2):46-50

72. Lapchak PA (2002) NXY-059. Centaur. Curr Opin Investig Drugs 3(12):1758-1762

73. Kuroda S, Tsuchidate R, Smith ML, Maples KR, Siesjo BK (1999) Neuroprotective effects of a novel nitrone, NXY-059, after transient focal cerebral ischemia in the rat. J Cereb Blood Flow Metab 19(7):778-787

74. Green AR, Lanbeck-Vallen K, Ashwood T, Lundquist S, Lindström Böö E, Jonasson H et al (2006) Brain penetration of the novel free radical trapping neuroprotectant NXY-059 in rats subjected to permanent focal ischemia. Brain Res 1072(1):224-226

75. Bath PM, Gray LJ, Bath AJ, Buchan A, Miyata T, Green AR (2009) Effects of NXY-059 in experimental stroke: an individual animal meta-analysis. Br J Pharmacol 157(7):1157-1171 
76. Lapchak PA, Song D, Wei J, Zivin JA (2004) Coadministration of NXY-059 and tenecteplase six hours following embolic strokes in rabbits improves clinical rating scores. Exp Neurol 188(2):279-285

77. Lees KR, Zivin JA, Ashwood T, Davalos A, Davis SM, Diener $\mathrm{HC}$ et al (2006) NXY-059 for acute ischemic stroke. N Engl J Med 354(6):588-600

78. Watanabe T, Tahara M, Todo S (2008) The novel antioxidant edaravone: from bench to bedside. Cardiovasc Ther 26(2):101114

79. Yoshida H, Yanai H, Namiki Y, Fukatsu-Sasaki K, Furutani N, Tada N (2006) Neuroprotective effects of edaravone: a novel free radical scavenger in cerebrovascular injury. CNS Drug Rev 12 (1):9-20 (spring)

80. Toyoda K, Fujii K, Kamouchi M, Nakane H, Arihiro S, Okada Y et al (2004) Free radical scavenger, edaravone, in stroke with internal carotid artery occlusion. J Neurol Sci 221 (1-2):11-17

81. Mishina M, Komaba Y, Kobayashi S, Tanaka N, Kominami S, Fukuchi $\mathrm{T}$ et al (2005) Efficacy of edaravone, a free radical scavenger, for the treatment of acute lacunar infarction. Neurol Med Chir (Tokyo) 45(7):344-348, discussion 8

82. Inatomi Y, Takita T, Yonehara T, Fujioka S, Hashimoto Y, Hirano $T$ et al (2006) Efficacy of edaravone in cardioembolic stroke. Intern Med 45(5):253-257

83. EAISG (2003) Effect of a novel free radical scavenger, edaravone (MCI-186), on acute brain infarction. Randomized, placebo-controlled, double-blind study at multicenters. Cerebrovasc Dis 15(3):222-229

84. Suda S, Igarashi H, Arai Y, Andou J, Chishiki T, Katayama Y (2007) Effect of edaravone, a free radical scavenger, on ischemic cerebral edema assessed by magnetic resonance imaging. Neurol Med Chir (Tokyo) 47(5):197-201, discussion 2

85. Yoshifumi T (ed) (2007) Benefits of pre-treatmetn with edaravone in tPA intravenous therapy for acute cerebral infarction. XXIIIrd International Symposium on Cerebral Blood Flow (abstract)

86. Diener HC, Lees KR, Lyden P, Grotta J, Davalos A, Davis SM et al (2008) NXY-059 for the treatment of acute stroke: pooled analysis of the SAINT I and II trials. Stroke 39(6):1751-1758

87. Sinha M, Anuradha H, Juyal R, Shukla R, Garg R, Kar A (2009) Edaravone in acute ischemic stroke, an Indian experience. Neurology Asia 14:7-10

88. Hishida A (2007) Clinical analysis of 207 patients who developed renal disorders during or after treatment with edaravone reported during post-marketing surveillance. Clin Exp Nephrol 11(4):292-296
89. Detaboada L, Ilic S, Leichliter-Martha S, Oron U, Oron A, Streeter J (2006) Transcranial application of low-energy laser irradiation improves neurological deficits in rats following acute stroke. Lasers Surg Med 38(1):70-73

90. Ilic S, Leichliter S, Streeter J, Oron A, DeTaboada L, Oron U (2006) Effects of power densities, continuous and pulse frequencies, and number of sessions of low-level laser therapy on intact rat brain. Photomed Laser Surg 24(4):458-466

91. Oron A, Oron U, Chen J, Eilam A, Zhang C, Sadeh M et al (2006) Low-level laser therapy applied transcranially to rats after induction of stroke significantly reduces long-term neurological deficits. Stroke 37(10):2620-2624

92. Lapchak PA, Salgado KF, Chao CH, Zivin JA (2007) Transcranial near-infrared light therapy improves motor function following embolic strokes in rabbits: an extended therapeutic window study using continuous and pulse frequency delivery modes. Neuroscience 148(4):907-914

93. Lampl Y, Zivin JA, Fisher M, Lew R, Welin L, Dahlof B, Andersson B, Perez J, Caparo C, Ilic S, Oron U (2007) Infrared laser therapy for ischemic stroke- a new treatment strategy: results of the NeuorThera Effectiveness and Safety Trial-1 (NEST-1). Stroke 38:1843-1849

94. Zivin JA, Albers GW, Bornstein N, Chippendale T, Dahlof B, Devlin $T$ et al (2009) Effectiveness and safety of transcranial laser therapy for acute ischemic stroke. Stroke 40(4):1359-1364

95. Del Zoppo GJ, Saver JL, Jauch EC, Adams HP Jr (2009) Expansion of the time window for treatment of acute ischemic stroke with intravenous tissue plasminogen activator. A science advisory from the American Heart Association/American Stroke Association. Stroke 40:2945-2948

96. Kitagawa Y (2006) Edaravone in acute ischemic stroke. Intern Med 45(5):225-226

97. Karbowski J (2007) Global and regional brain metabolic scaling and its functional consequences. BMC Biol 5:18

98. Gelineo S (1964) Organ systems in adaptation: the temperature regulating system. In: Dill DB (ed) Adaptation to the environment. Handbook of physiological science, section 4. Williams \& Wilkins, Baltimore, pp 259-282

99. Durnin JVGA (1981) Basal metabolic rate in man. FAO/WHO/ UNU Expert Consultation on Energy and Protein Requirements

100. Zhang Z, Zhang L, Yepes M, Jiang Q, Li Q, Arniego P et al (2002) Adjuvant treatment with neuroserpin increases the therapeutic window for tissue-type plasminogen activator administration in a rat model of embolic stroke. Circulation 106(6):740-745

101. Henninger N, Bratane BT, Bastan B, Bouley J, Fisher M (2009) Normobaric hyperoxia and delayed tPA treatment in a rat embolic stroke model. J Cereb Blood Flow Metab 29(1):119-129 